amplification, ploidy, raised serum activities of ferritin and neurone specific enolase. ${ }^{15}$ Whether there is a progression from good to bad features remains controversial, although most of the evidence suggests that these features are constant within a given tumour. ${ }^{16}$

\section{EFFECTIVENESS AND FEASIBILITY OF SCREENING}

This study was set up to assess the feasibility of screening for neuroblastoma. Clearly this is possible and a high compliance rate can be achieved by using health visitors. By drying filter paper a low rate of taking repeat samples should be possible and there is a low false positive rate.

The authorities in Japan were convinced of the efficacy of screening so that since 1985 all babies in Japan have been offered screening. ${ }^{6}$ However, there is as yet no convincing evidence of a fall in the death rate from neuroblastoma in Japan. ${ }^{1718}$ Because screening may detect silent cases of neuroblastoma, which might otherwise have spontaneously regressed, the only way to evaluate screening is a controlled trial comparing large screened and contemporaneously unscreened populations. Such a study is underway in Quebec ${ }^{13}$ and another has been proposed for the United Kingdom. ${ }^{19}$ Screening at 6 months of age has missed cases of neuroblastoma in this study, in Japan, ${ }^{20}$ and in Quebec (W G Woods, personal communication). This, together with the undoubted increase in incidence of neuroblastoma in screened populations as a result of the identification of silent cases calls into question the age at which children should be screened or indeed whether they should be screened at all. The age related mortality characteristics of neuroblastoma suggest that screening at around 15-18 months of age may well reduce the incidence of both false negative cases and silent neuroblastomas but whether this would influence the course of fatal cases requires further investigation. A definitive study of neuroblastoma screening is essential and will probably require one million babies to be screened and a similar number of controls. The results of such studies are awaited with interest before neuroblastoma screening is implemented in many other countries.

We thank the North of England Children's Cancer Research Fund, the Neuroblastoma Society, and the special trustees of the Newcastle hospitals. This study would not have been possible without the willing support of the health visitors of all four districts.

1 Craft AW, Amineddine HA, Scott JES, Wagget J. The Northern Region Children's Malignant Disease Registry, 1968-1982: incidence and survival. Br 7 Cancer 1987;56:853-8.

2 Shafford EA, Rogers DW, Pritchard J. Advanced neuroblastoma: improved response rate using a multiagent regimen (OPEC). 7 Clin Oncol 1984; $742-7$.

3 Evans AE, D'Angio GJ, Propert K, Anderson J, Hann HW. Prognostic factors in neuroblastoma. Cancer 1987;59:1853-9.

4 Tuchman M, Ramnaraine MLR, Woods WG, Krivit W. Three years experience with random urinary homovanillic acid and vanillylmandelic acid levels in the diagnosis of neuroblastoma. Pediatrics 1987;79:203-5.

5 Sawada T, Hirayama M, Nakata T, Takeda T, Takasugi N, Mori T, et al. Mass screening for neuroblastoma in infants in Japan. Interim report of a mass screening study group. Lance 1984;ii:271-3.

6 Sawada T, Matsumara T, Matsuda Y, Kawakatsu H. Neuroblastoma studies in Japan. In: Miller AB, Chamberlain J, Day NE, Hakama M, Prorok PC, in Japan. In: Miller AB, Chamberlain J, Day NE, Hakama M, Prorok PC, eds. Co.

7 Nishi M, Miyake H, Takeda T, Shimada M, Takasugi N, Sato Y, et al. Effects of mass screening of neuroblastoma in Sapporo City. Cancer 1987;60:433-5. 8 Dale G, McGill A, Seviour JA, Craft AW. Urinary excretion of HMMA and homovanillic acid in infants. Ann Clin Biochem 1988;25:233-6.

9 Seviour JA, McGill AC, Dale G, Craft AW. Method of measurement of urinary homovanillic acid and vanillylmandelic acid by gas chromatography mass spectrometry suitable for neuroblastoma screening. $\mathcal{f}$ Chromatogr 1988;432 273-7.

10 Cole M, Parker L, Craft AW, Bell S, Dale G, McGill AC, et al. Creatinine related reference ranges for urinary HVA and VMA at 6 months of age. Arch Dis Child (in press)

11 Mizuta M, Umisa $H$. Utilisation of wet paper urine specimens in mass screening for neuroblastoma-the problem of bacterial contamination. fapan fournal of Public Health 1988;35:179-83.

12 Ruthven CRJ, Sandler M. Neurogenic amines and secreting tumours. In: Brown SS, Mitchell F, Young DS, eds. Chemical diagnosis of disease. Brown SS, Mitchell F, Young DS, eds. Chemi

13 Tuchman M, Lemieux B, Auray-Blais C, Robison LL, Giguere R, McCann $\mathrm{MT}$, et al. Screening for neuroblastoma at 3 weeks of age; methods and preliminary results from the Quebec Neuroblastoma Screening Project. Pediatrics 1990;86:765-73.

14 Nishi M, Miyake H, Takeda T, Shimada M, Takasugi N, Sato Y, et al. Incidence of neuroblastoma in Sapporo City. F Pediatr Surg 1990;25:545-6.

15 Look AT, Hayes FA, Shuster JJ, Douglass EC, Castleberry RP, Bowman LC, et al. Clinical relevance of tumor cell ploidy and $n$-myc gene amplification in childhood neuroblastoma: a Pediatric Oncology Group Study. 7 Clin Oncol 1991;9:581-91.

16 Brodeur GM, Hayes FA, Green AA, Casper JT, Wasson J, Wallach S, et al. Consistent $\mathrm{N}$-myc copy number in simultaneous or consecutive neuroConsistent $\mathrm{N}$-myc copy number in simultaneous or consecutive neuro-
blastoma samples from sixty individual patients. Cancer Res 1987;47: 4248-53.

17 Hanawa Y, Sawada T, Tsunoda A. Decrease in childhood neuroblastoma death in Japan. Med Pediatr Oncol 1990;18:472-5.

18 Cole M, Parker L, Craft AW. Decrease in childhood neuroblastoma death in Japan. Med Pediatr Oncol 1992;20:84-5.

19 Parker L, Craft AW, Dale G. Screening for neuroblastoma. Background preliminary experience in the North of England and proposals for an evaluative study. In: Miller AB, Chamberlain J, Day NE, Hakama M, Prorok PC, eds. Cancer screening. Cambridge: Cambridge University Press, 1991:337-52.

20 Nishi M, Miyake H, Takeda T, Takasugi N, Sato Y, Hanai J, et al. Cases of neuroblastoma missed by the mass screening programs. Pediatr Res 1989;26:603-9.

(Accepted 9 September 1992)

\title{
Are patient consent forms for research protocols easy to read?
}

Royal Brompton National Heart and Lung Hospital, London SW3 6NP

Kim A Priestley, research fellow

Claire Campbell, business administrator

Christopher B Valentine, research fellow

David M Denison, chairman, ethics committee

Nigel P Buller, senior lecturer

Correspondence to:

Dr K A Priestley,

Department of Invasive

Cardiology, Royal

Brompton National Heart

and Lung Hospital, London

SW3 6NP.

BMF 1992;305:1263-4

\section{Kim A Priestley, Claire Campbell, Christopher B \\ Valentine, David M Denison, \\ Nigel P Buller}

Written informed consent is an integral part of any clinical research protocol. It is solicited with a written consent form after a brief oral explanation of the project. Informed consent demands that the written explanation of the research project is easy to read and understand. Reading difficulty can be measured with several scoring systems. ${ }^{1}$ Using established measurements of readability, we compared the readability of consent forms with that of daily newspapers.

\section{Methods and results}

We examined the consent forms of 50 protocols for research on adults. These were all the approved protocols submitted to the ethics committee of the
Royal Brompton National Heart and Lung Hospitals between 22 July 1991 and 8 April 1992. The consent forms were analysed with Microsoft Word for Windows, a computer software package that provides statistics on readability. Several variables were counted: words, characters, paragraphs, sentences, sentences per paragraph, words per sentence, and characters per word. Readability was measured with the Gunning fog index, the Flesch-Kincaid index, and the Flesch reading ease. These indices are derived from the length of sentences and the number of syllables per word or per 100 words.

For comparison we analysed the editorial and comment sections of 10 national newspapers published on one particular day (Daily Express, Daily Mail, Daily Mirror, Daily Star, Daily Telegraph, Guardian, Independent, Sun, Times, and Today). The mean scores for the consent forms and the newspapers were then compared by Student's $t$ test for unpaired data. Comparisons were also made with a mean score calculated for the three newspapers with the widest readership (Sun, Daily Mirror, and Daily Mail). ${ }^{2}$

The consent forms and newspaper editorials varied widely in length. This was reflected in the numbers of paragraphs, sentences, words, and characters used 


\begin{tabular}{|c|c|c|c|c|c|c|c|}
\hline & \multicolumn{3}{|c|}{ Newspapers } & \multicolumn{3}{|c|}{ Consent forms } & \multirow[b]{2}{*}{$\mathrm{p}$ Value } \\
\hline & Range & Mean & $\begin{array}{l}95 \% \text { Confidence } \\
\text { interval }\end{array}$ & Range & Mean & $\begin{array}{l}95 \% \text { Confidence } \\
\text { interval }\end{array}$ & \\
\hline Words & $128-928$ & 447 & 311 to 638 & $163-1124$ & 386 & 336 to 436 & NS \\
\hline Characters & $592-4616$ & 2288 & 1453 to 3123 & $719-5302$ & 1796 & 1562 to 2029 & NS \\
\hline Paragraphs & 4-21 & 12 & $8 \cdot 5$ to 16 & $2-19$ & 6 & $5 \cdot 1$ to $7 \cdot 02$ & 0.004 \\
\hline Sentences & $10-48$ & 28 & 20 to 36 & $6-51$ & 17 & $15 \cdot 5$ to 20 & 0.019 \\
\hline $\begin{array}{l}\text { Sentences per } \\
\text { paragraph }\end{array}$ & & & 1.8 to 4.3 & & & 2.9 to $4 \cdot 1$ & \\
\hline Words per sentence & $11 \cdot 4-20 \cdot 8$ & $\begin{array}{r}2 \cdot 8 \\
16 \cdot 5\end{array}$ & $\begin{array}{c}1.8 \text { to } 4.3 \\
14.3 \text { to } 18 \cdot 6\end{array}$ & $\begin{array}{l}1 \cdot 1-11 \\
14-28\end{array}$ & $\begin{array}{r}3.3 \\
21.9\end{array}$ & $\begin{array}{l}2 \cdot 9 \text { to } 4 \cdot 1 \\
21 \text { to } 22\end{array}$ & $<0.0001$ \\
\hline Characters per word & $4 \cdot 3-5 \cdot 1$ & $4 \cdot 8$ & $4 \cdot 6$ to $4 \cdot 9$ & $4 \cdot 1-5 \cdot 1$ & $4 \cdot 6$ & $4 \cdot 5$ to $4 \cdot 7$ & NS \\
\hline Flesch reading ease ${ }^{\star}$ & $39 \cdot 6-71$ & 57.5 & 51 to 64 & $30-72$ & $52 \cdot 2$ & $49 \cdot 6$ to $54 \cdot 8$ & NS \\
\hline $\begin{array}{l}\text { Flesch-Kincaid } \\
\text { index } \dagger\end{array}$ & $6 \cdot 5-11 \cdot 8$ & $9 \cdot 27$ & $8 \cdot 2$ to $10 \cdot 4$ & $8 \cdot 1-15 \cdot 3$ & $11 \cdot 21$ & $10 \cdot 7$ to $11 \cdot 7$ & 0.003 \\
\hline Gunning fog index $\dagger$ & $9 \cdot 2-14 \cdot 3$ & 11.9 & $10 \cdot 7$ to $13 \cdot 1$ & $10-17 \cdot 6$ & $13 \cdot 7$ & $13 \cdot 1$ to $14 \cdot 2$ & 0.008 \\
\hline
\end{tabular}

${ }^{\star}$ Lower score indicates harder to read. †Higher score indicates harder to read.

(table). There was no significant difference in the numbers of words and characters between the consent forms and the newspaper editorials. Consent forms, however, had significantly fewer paragraphs and sentences. This was reflected in the readability scores. Consent forms were significantly more difficult to read than newspaper editorials when assessed by the Flesch-Kincaid and Gunning fog indices.

Compared with the mean values for the three most widely read newspapers, 46 consent forms had more sentences per paragraph and all the consent forms had longer sentences. The number of characters per word in the consent forms was similar to the mean for the three newspapers. Forty eight consent forms were more difficult to read than the three newspapers (as shown by the mean value) according to the FleschKincaid index, 45 according to the the Gunning fog index, and 37 according to the Flesch reading ease.

\section{Comment}

Good clinical practice requires that a patient's informed consent is obtained before that person is entered into a clinical trial. ${ }^{3}$ This demands clear oral and written communication between the doctor and patient. Consent forms in this study were more difficult to read than newspaper editorials. Poor readability was caused by the use of long paragraphs and long sentences, not by the excessive use of long words. This study supports the first of Gunning's 10 principles of clear writing-"Keep sentences short." If we are to fulfil our obligations the readability of consent forms must be improved. These data suggest that shorter sentences would help make consent forms easier to read.

KAP was suported by the Charles Wolfson Charitable Trust. We thank Miss V Pilcher for secretarial help.

1 Gunning R. The technique of clear writing. Rev ed. New York: McGraw-Hill, 1971.

2 Joint Industry Committee for National Readership Surveys. National readership survey; fuly-Dec 1991. London: JICNRS, 1992.

Committee of Proprietary Medicinal Products. Working Pary on the Efficacy of Medicinal Products. Good clinical practice for trials on medicinal products in the European Community. Brussels: CPMP, 1991. (111/3976/88-EN.)

(Accepted 28 October 1992)

\section{Should general practitioners have access to paediatric cardiologists?}

\section{J A Rushforth, N Wilson}

Department of Paediatrics, General Infirmary at Leeds, Leeds LS2 9NS

J A Rushforth, registrar

\section{Killingbeck Hospital,} Leeds LS14 6UH

$\mathrm{N}$ Wilson, consultant

paediatric cardiologist

Correspondence to:

Dr Rushforth.

$B M 7$ 1992;305:1264-5

Source of referrals to paediatric cardiology clinic

\begin{tabular}{lc}
\hline Source & No \\
\hline $\begin{array}{l}\text { Community: } \\
\text { General practitioner }\end{array}$ & 129 \\
$\begin{array}{l}\text { Community medical } \\
\text { officer }\end{array}$ & 17 \\
Paediatrician & 38 \\
\hline Total & 184 \\
\hline
\end{tabular}

The prevalence of congenital heart disease in the population approaches $1 \%$, but many children are found to have innocent heart murmurs. ${ }^{1}$ We sought to establish the reasons for referral to a paediatric cardiology outpatient clinic and whether there was a case for general practitioners to continue to have direct access to the service.

\section{Patients, methods, and results}

The case notes of all new patients attending a paediatric cardiology outpatient clinic were reviewed. The clinic was not at a tertiary referral centre. General practitioners who referred patients worked mainly in inner city and suburban practices in Leeds. Chest radiography, electrocardiography, and echocardiography with Doppler studies were available in the clinic.

New patients made up $54 \%$ of all patients seen over the 13 months of the study. The table shows the source of these referrals. Of the 184 new patients, 167 were referred with an asymptomatic murmur, 15 were referred to exclude familial cardiac disease or cardiac manifestations of systemic disease, and only two were referred with symptoms (tachycardia). Altogether 142 patients were found to have either an innocent murmur or a normal heart on examination. Fourteen had a ventricular septal defect, nine pulmonary stenosis, four ductus arteriosus, two arrhythmia, and 13 more complex congenital heart disease.

Of the 129 referrals from general practitioners, 126 were made because of an asymptomatic murmur and the remainder because of an irregular heart rate. Fourteen patients $(11 \%)$ were found to have a structural abnormality or an important arrhythmia. Seven had a ventricular septal defect: one aortic stenosis, one atrial septal defect, one ductus arteriosus, two mitral valve prolapse, and two supraventricular tachycardia. The general practitioners offered a diagnosis in 43 cases $(33 \%)$ and were correct in $36(84 \%)$. When the diagnosis was incorrect there were no serious implications. An innocent murmur had been diagnosed in three patients, who were found to have a ventricular septal defect, a mitral valve prolapse, and an aortic stenosis. Four patients referred with possible structural abnormalities were found to have innocent murmurs.

Referrals from paediatricians made up $21 \%$ of new patients seen. All these patients were referred with murmurs. Twenty $(53 \%)$ had a structural cardiac abnormality. A diagnosis was offered in $27(71 \%)$ of the 38 cases and was correct in $12(44 \%)$. Again, incorrect diagnosis had no serious implications.

One third of all new patients attending the clinic had an investigation. Chest radiography and electrocardiography were performed in 55 patients and echocardiography in 72 . For all new patients referred the median interval between referral and consultation was 27 (range 0-76) days. For referrals from general practitioners the median interval was 29 (7-64) days. This delay is acceptable for non-urgent referrals and compares favourably with waiting lists for medical and surgical paediatric outpatient clinics in this hospital during the study.

\section{Comment}

The pathological yield of $11 \%$ among referrals made by general practitioners seems to support the case for general practitioners having direct access to a paediatric cardiology service. Although the general practitioners made a tentative diagnosis for only one third of their referrals, it was correct in $84 \%$ of cases. These findings 